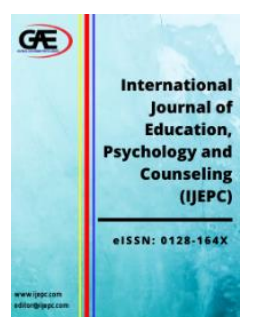

International Journal of Education, Psychology and Counselling (IJEPC)

Journal Website: http://ijepc.com/ eISSN: 0128-164X

\title{
LANGUAGE DISORDERS, DIAGNOSIS AND TREATMENT FOR CHILDREN: ARABIC-SPEAKING PRESCHOOL-CHILDREN IN FOCUS
}

\author{
Alaa Majed Alkhlouf ${ }^{1}$, Najihah Abd Wahid ${ }^{2}$, Mustafa Kazakzeh ${ }^{3}$, Anas Mohd Yunus ${ }^{4}$ \\ 1 Universiti Sultan Zainal Abidin, Malaysia \\ Email: Alaa.unisza@gmail.com \\ 2 Universiti Sultan Zainal Abidin, Malaysia \\ Email: anajihah@unisza.edu.my \\ 3 Universiti Sultan Zainal Abidin, Malaysia \\ Email: mustafa.unisza@gmail.com \\ $4 \quad$ Universiti Sultan Zainal Abidin, Malaysia \\ Email: anas@unisza.edu.my \\ * Corresponding Author
}

\section{Article Info:}

Article history:

Received date: 19.12 .2018

Revised date: 31.12 .2018

Accepted date: 14.06.2020

Published date: 15.06 .2020

\section{To cite this document:}

Alkhlouf, A. M., Abd Wahid, N., Kazakzeh, M., \& Yunus, A. M. (2020). Language Disorders, Diagnosis and Treatment for Children: Arabic-Speaking Preschool-Children in Focus. International Journal of Education, Psychology and Counseling, 5 (35), 298-305.

DOI: $10.35631 /$ IJEPC.5350025.

\begin{abstract}
:
The study plans to analyze diagnoses and treatments to language disorders among Arabic-speaking children. The paper regards language disorder as a major problem facing under-aged children in many Arab societies. Since human communication is incomplete without language, there is a need to identify the treatment and diagnosis of language disorder on Arab pre-school children residing in Terengganu, Malaysia. As such, the study examines language disorder among Arabic-speaking minors during early-stage development and explores its influences in Arab-communities. The study highlights methods of healing under-aged children that fall under this category. A total of 50 participants aged between 3-5 years were used for the sampling method. Standardized assessment tools were purposefully applied to differentiate articulation from language disorder, and fluency and speech turmoil were recognized. The result indicates that language disorder is uncontrollable for minors, most especially, in the absence of counselling services. Hence, the current study complements the previous studies on language disorder by highlighting diagnosis, treatments, and services available for victims of language disorder.
\end{abstract}

Keywords:

Diagnosis, Treatment, Minor, Language Disorder 


\section{Introduction}

Language is considered as one of the most important means of communication because it consists of skills such as speaking, listening, reading, and writing. Each of these skills represents one of the means of acquiring knowledge and transfer life experiences. Language is considered as one of the most important characteristics bestowed by the Almighty on a human being. It is only human beings that can use the language whether in spoken or written communication irrespective of their different environments (Al-Nubi, 2011). Language is the most important method of psychological communication through which the personality of a person can be identified. It is recognized as an important cultural function. It is a means of spreading culture, knowledge, science and literature from one society to another and from one generation to another. It is the basis of the linguistic civilization of human development through which human history is transmitted (Amguru, 2012).

Language disorder affects children in understanding oral language (Bishop et al., 2016) that consequently results in social and emotional problems (St Clair et al., 2011). The inevitability of Language disorder influences some children than others (Conti-Ramsden et al., 2019), although, recent research indicates that individual differences may be partially caused by genetic effects (Newbury et al., 2019). Language Disorder (LD) generates internal signs such as social anxiety and somatic complaints (St Clair, et al. 2010). LD as receptive or expressive challenges observed in children is a complicated developmental condition that has different behavioural appearances (Prelock, Hutchins \& Glascoe, 2008).

Despite that Language Disorder (LD) is not a new concept, it is essential to empirically present diagnosis and treatment to Language Disorder (LD) among Arabic-speaking children. Concluded studies showed that LD may likely deactivate other areas of human development including vocational choices, psychosocial domains and academic performance. Therefore, the possible treatment and diagnosis to LD challenge for under-aged children is a much-demanding focus in the linguistic study before formal education. The essence of conducting this study is to show that victims of language disorder deserve adequate attention and recognition in the society. The current study advocates that language disorder patients require medical, academical, encouragement services and humanitarian support in the community.

\section{Concept of Language}

Al-Farmawi (2009) believed that language is a set of symbols, either sound or non-sound signals, such as gestures and facial expressions, used by individuals to communicate and interact with each other (Al-Farmawi 2009). Mattingly (1998) found that the use of language means that our language consists of meanings, and therefore it represents a context of communication used in society. Al-Zariqat (2005) emphasized that language consists of using all means of conveying information from sender to receiver in human communication. AlZariqat confirmed that an individual has the advantage of developing language, spoken, written or sign language. Arar and Al-Hashimi (2016) submitted that language is developed through visual skills such as discernment, identification, absorption and reflection; audio skills; verbal expression and formation of concepts; attention, memory and gesture; and well-being of body and thought.

\section{Concept of Language Disorder}

Language disorders are a broad area of learning disabilities, which are essentially due to functional neurological dysfunction in the central nervous system where the individual's ability to understand and use language is affected by learning disabilities. By close observations, it could be understood that all educational tasks, including the use of language such as listening 
thinking, speaking, reading, writing and mathematics can only be learned through language (Al-Farmawi, 2009).

Paul and Norbury (2011) stated that the term 'language disorder' refers to a child who usually produces a limited set of speech sounds, making speech output incomprehensible, and thus influencing the child's ability to communicate with others. Paul and Norbury further explained that language disorder is also used to describe children who do not acquire language as expected due to some reasons. Al-Dukhi and Al-Aqeel (2010) asserted in their book "Speech disorders in children" that language disorder refers to lack of understanding language and or inability to express one's self, which is reflected in the speech and understanding of reading or writing. Bishop, Snowling, Thompson, Greenhalgh, \& Consortium (2016) agreed that the term 'language disorder' refers to children with language difficulties, which results in obstacles to communication or learning in their daily life. Abdul Ghani (2010) noted that language disorders are early indicators of learning existence, as people with language disorders have difficulty in producing speech and using spoken language as well as reading and writing.

Fatima (2016) believed that language disorder is a concept that refers to the inability of an individual to produce speech in a comprehensible form or unable to express the ideas in proper words. Therefore, a language disorder is defined as difficulties to produce or receive linguistic elements regardless of the nature of language, ranging from its extent of total comprehension or speech to the apparent weaknesses in producing and respecting grammatical rules (Amrani, 2014). Mahmoud (2007) also noted that language disorders are difficulties in receptive language, as people with language disorder have difficulties in receiving and understanding language. They also have difficulties in expressing themselves verbally.

Al-Dabbas (2013) submitted that linguistic disorders appear as:

\section{Speech Disorders}

Speech is the human device of language through which a particular social system is formed within society. The problem with speech is poor linguistic output, delayed speech in children in early childhood (2-5 years), reluctance in speech (stuttering), seizure of tongue (stammering) and the use of strange words that are meaningless. It might appear in the process of the pronunciation of words, and they are classified into two forms such as omission disorders and substitution disorders. In omission disorders, the individual omits one or more characters from a word, such as Khauf - Kharouf. The case of omission is acceptable and normal until the school years. An individual who frequently omits characters in spoken words suffers from disorders related to substitution. It is to replace an individual's character with another character in the word such as Sakeena - Steena and Khushun - Hushun. Disorders also consist of addition, where the child adds a new character to the spoken word such as Lu'baat instead of Lu'bah (Al-Rousani, 2000).

\section{Poor Speech Output}

This occurs in terms of producing meaningless sounds and relying on movements and signals. It also refers to the child's unclear and incomprehensible expressions and replies to questions with 'yes' or 'no' or one word. These cases are frequent among children of 4-5 years.

\section{Fast Speech}

This refers to compression of words or speech without reasons and repetition of unnecessary phrases through excessive speed in speech, where the speech becomes compressed to the extent 
that the listener cannot understand the message due to lack of consistency in terms of verbal and psychological aspects (Haj Muhammad, 2008).

\section{Aphasia}

This word is derived from the Greek language that means "loss of speech". In medical term, aphasia means the inability to use oral and written language, where it could be considered a term that refers to the disorder or linguistic weakness that occurs in the human and leads to difficulty in understanding the language or ability to write and read (Amsaguru, 2012).

\section{Sound Disorders}

This is classified into several disorders, including phonetic rhythm disorders which include high and low sounds, a discrepancy in vocal patterns, stumbling sound, and thick sound. Sound disorders have various causes including dysfunction in the mechanism of vocal cords as well as sound pattern in its intensity. In this situation, the sound becomes inappropriate for the speaker's age and gender (AL-Dabbas, 2013).

\section{Speech Disorders Resulting from The Lack of Hearing Capacity}

These disorders vary in their degree of impact on the patient. It could be weak, medium and severe and affects the age period of the child who suffers from the hearing disorder. A child who loses hearing in early childhood cannot acquire language, which results in a lack of ability to speak, but the delayed disorder has little effect on language acquisition (Al-Dabbas, 2013). From the above forms, it is certain that language disorders negatively affect language output and also affect social productivity, where there are defects amongst the linguistically disturbed students compared to ordinary people. Consequently, academic and cognitive difficulties occur due to linguistic disruption, as pointed out by Zariqat (2005).

\section{Research Problem}

Bishop et al., (2017) contended that language turmoil victim encounter difficulties in the use of language contents during social interaction. Reilly et al., (2009) considered language disorder as a prevalent challenge faced by minors during childhood-stage. Most existing literature overlooked the treatment and diagnosis of language disorder in Arabic-speaking societies. Moreover, the studies conducted for sub-Saharan Africa could not be applied in the Gulf region due to the dissimilar targeted group. Besides, using the outcomes of sub-Saharan Africa to assess Gulf countries is unethical in the academic environment.

Scanty researches largely focus on treating victims of language disorder (Bartlett et al. 2008). Blustein et al., (2020) observed that impaired communication and the health and safety risks of communication disability increased significantly in the past few years. Sensory impairments such as weak vision and poor hearing were identified as the major obstacle behind the communication problem. Wallhagen \& Reed (2018) argued that cost and access to remedytools pose an additional challenge to the cure of language disorder.

In view of this, the current study presents treatment to language disorder challenge in Arabsocieties, specifically, among Arabic-speaking under-aged children. The study sought to explore sustainable solutions to language disorders starting from articulation, expressive language, receptive language, fluency and voice disorders among Arabic-speaking children in Arabic communities. 


\section{Methodology}

Sampling technique was applied to Arabic-speaking preschools children studying in Terengganu, Malaysia. After obtaining each school principal's consent, participants were randomly selected. A consent form accompanied with reasons for conducting the study was sent to parents or guardians through school authority. The role of Arabic speaking children in the survey was communicated through the letter for parent or guardian's approval.

Language disorder assessments were carried out at the school premises. Participants were separately assessed by the researcher. A direct assessment was conducted with a standardized test tool to examine voice, fluency and language disorders in the selected children. A pilot study was used to identify assessment issues, clarify study design and amend research procedures. The pilot testing exposed children facing difficulties in recognizing structures and contents of language. For clarification purpose, the children were randomly examined in a quiet place in the school environment.

\section{Analysis and Discussion}

Participants were classified into three different groups based on their respective age, namely, 3 years, 4 years and 5 years old. Absence of the signs of fluency and difficulties in terms of language comprehension shows the gravity of language disorder among the focused group. The victims of language disorder were identified as children having no skill in language fluency and articulation.

A predetermined percentage was used to identify articulation, receptive and expressive language disorders in the study sample. The outcomes from this identification-process were relatively low when compared with standardized language proficiency result. Comparison of common rates across the three age groups showed no significant difference in articulation, fluency, receptive and expressive language disorders. However, there was a significant difference in the phonetic-sound of these three age-groups.

Diagnostic instruments were used to estimate the differences in language disorder challenge experienced by Arabic-speaking children in Terengganu, Malaysia. The percentage of language disorders found in this study was significantly higher than that of other states and regions. Data collection method adopted to identify these children also shared in the high percentage of language disorders in the research outcome. The high rate of articulation and fluency disorders significantly constitute the increase-level of language disorders among children. The high percentage of language disorders discovered in this study was also caused by the age range of the participants. The high prevalence rates of language disorders detected in this study have no relationship with the exposure to multiple languages in Terengganu state, Malaysia. Participants with detrimental health status were excluded from the language assessment test. The findings show that a considerable number of Arabic-speaking children in Terengganu need language skills and services. However, few language service-providers exist in the state, particularly, for Arabic-speaking children.

One of the most significant uniqueness of this study is the application of direct assessment procedure. The formation of a normative sample remains debatable as Pena, Spaulding \& Plante (2006) argued that the normative sample may minimize identification accuracy. Notwithstanding that position, certain studies like Dunn \& Dunn (1997); Gillam \& Pearson (2004); Semel, Wiig \& Secord (2003) added participants with language disorders in the normative sample. 


\section{Perspectives and Concluding Thoughts}

The result of this study unveils the high-rate of language disorders in Arabic-speaking preschool-age children in Terengganu, Malaysia. The current study contributes to the limited data available for diagnosing language disorders and recommends the increment in language services across the state. The study encourages stakeholders like government, universities, educational and health care system to develop strategies and integrate initiatives to fulfil the needs of language disorder victims in societies.

The treatment and diagnosis of language disorders, as mentioned by Fatima (2016) in her article entitled "language disorders and communication issues in children", is the consistent efforts of an integrated team consisting of a group of people including medical doctors, language, speech and hearing specialists, neurologists, and psychologists. This could be used for linguistic problems. Al-Dabbas (2013) recommended that the case should be reported to a doctor who specializes in neurological diseases. The doctor is expected to address the patient's neurological and physiological problems, and then send the patient to language specialists and psychologists to conduct other necessary examinations on the situation and its history of development.

The aforementioned suggestion is also confirmed by Al-Dukhi and Aqeel (2010), that there are general considerations in addressing language disorders. A treatment plan is formulated according to the symptoms of language disorder rather than its causes. Therefore, the treatment plan is linked to the evaluation results. Al-Dukhi and Aqeel pointed out that the treatment of language disorder is not solely drugs or surgery as it is based on therapeutic programs aimed at improving the patient's language performance. This could be achieved through treatment sessions. However, doctors and specialists in neurology and psychiatry recommend the use of drugs in cases where the disorder is caused by other problems (such as epilepsy, attention deficit and hyperactivity). The use of hearing aids is also considered important in the case of communication for children, and it helps in the process of treatment. Therefore, it is preferable to follow the instruction-processes established by neurologists, psychologists, language specialists and medical doctors while controlling language disorder challenges in societies.

\section{References}

Abdul Ghani, Mithal. (2010). Children's learning disabilities. Center for Research and Educational Studies, (10).

Ak-Hashimi, Ikram; Arar, Samia (2016). Language disorders and communication diagnosis and treatment. Journal of Humanities and Social Sciences, (24).

Al-Dabbas, Sadiq Youssef (2013). Language disorders and treatment. Journal of Al-Quds Open University for Research and Studies, 1 (2).

Al-Faqa'awi, Jamal Rashad Ahmad. (2009). The effectiveness of a proposed program in the treatment of spelling learning difficulties among Seventh Grade Students in Khan Younis (Master's degree thesis), Islamic University.

Al-Farmawi, Hamdi Ali (2009). Speech disorders (speech, pronunciation, language, sound). Amman: Dar Al-Safa for Publishing and Distribution, vol. 1.

Al-Haj Mohammed, Nozha Amir (2008). Language and speech disorders and treatment. Children of the Gulf. Retrieved from: www.gul kids.com.

Al-Nubi, Mohamed Ali. (2011). Learning difficulties between skills and disorders. Dar al-Safa for Publishing and Distribution, vol. I.

Al-Rousan, Farouk. (2000). Introduction to language disorders. Riyadh. Dar Al - Zahraa for Publishing and Distribution, vol. I. 
Amguru, Arrows (2012). Abyssinia types and treatment. Retrieved from: Www.marocpress.com

Bartlett, et al. 2008. Impact of patient communication problems on the risk of preventable adverse events in acute care settings. Canad Med Assoc J. 178(2):1555-1562.

Bishop, D. V. M., Snowling, M. J., Thompson, P. A., Greenhalgh, T., Adams, C., Archibald, L., \& Consortium, C. (2016). CATALISE: A multinational and multidisciplinary delphi consensus study. Identifying language impairments in children. PloS One, 11(7), https://doi.org/10.1371/journal.pone.0158753 ARTN e0158753.

Bishop, D. V. M., Snowling, M. J., Thompson, P. A., Greenhalgh, T., Adams, C., Archibald, L., et al. (2017). Phase 2 of CATALISE: A multinational and multidisciplinary Delphi consensus study of problems with language development: Terminology. Journal of Child Psychology and Psychiatry and Allied Disciplines, 58(10), 1068-1080. https ://doi.org/10.1111/jcpp.12721.

Blustein, et al. 2020. It's time to take hearing seriously. Joint Comm J Qual Patient Safety.46:53-58.

Conti-Ramsden, G., Mok, P., Durkin, K., Pickles, A., Toseeb, U., \& Botting, N. (2019). Do emotional difficulties and peer problems hew together from childhood to adolescence? The case of children with a history of Developmental Language Disorder (DLD). European Child \& Adolescent Psychiatry, 28(7), 993-1004. https://doi.org/10.1007/s00787-018-1261-6.

Dunn, L. M., \& Dunn, L. M. (1997). Peabody Picture Vocabulary Test-III. Circle Pines, MN: AGS.

Gillam, R. B., \& Pearson, N. A. (2004). TNL: Test of Narrative Language. Austin, TX: ProEd.

Imrani, Zuhair. (2014). The nature of dyslexia adversity between writing and developmental learning difficulties". Human and Social Journal, (16).

Mahmoud, Olfat (2007). Some personal difficulties and social skills of children with learning disabilities (Master's degree thesis). Beirut Arab University, Lebanon.

Mattingly, I., G. (1985). Speech cues and sign stimuli. American Scientist, 60-327-337.

Newbury, D. F., Gibson, J. L., Conti-Ramsden, G., Pickles, A., Durkin, K., \& Toseeb, U. (2019). Using polygenic profiles to predict variation in language and psychosocial outcomes in early and middle childhood. Journal of Speech, Language, and Hearing Research, 62(9), 3381-3396. https://doi.org/10.1044/2019_jslhr-1-19-0001.

Paul, R. \& Norbury, C. (2011). Language disorders from infancy through adolescence: Listening, Speaking, Reading, Writing, and Communicating. Mosby, an imprint of Elsevier Inc.websites

Pena, E. D., Spaulding, T. J., \& Plante, E. (2006). The composition of normative groups and diagnostic decision making: Shooting ourselves in the foot. American Journal of Speech-Language Pathology, 15(3), 247-254.

Prelock, P. A., Hutchins, T., \& Glascoe, F. P. (2008). Speech language impairment: How to identify the most common and least diagnosed disability of childhood. The Medscape Journal of Medicine, 10(6), 136.

Reilly, S., Onslow, M., Packman, A., Wake, M., Bavin, E. L., Prior, M., . . . Ukoumunne, O. C. (2009). Predicting stuttering onset by the age of 3 years: A prospective, community cohort study. Pediatrics, 123(1), 270-277.

Semel, E., Wiig, E. H., \& Secord, W. A. (2003). Clinical Evaluation of Language Fundamentals-Fourth Edition. San Antonio, TX: The Psychological Corporation.

St Clair, M. C., Pickles, A., Durkin, K., \& Conti-Ramsden, G. (2011). A longitudinal study of behavioral, emotional and social difficulties in individuals with a history of specific 
language impairment (SLI). Journal of Communication Disorders, 44(2), 186-199. https://doi.org/10.1016/j.jcomdis.2010.09.004.

St Clair, M. C., Pickles, A., Durkin, K., \& Conti-Ramsden, G. (2010). A longitudinal study of behavioral, emotional and social difficulties in individuals with a history of specific language impairment (SLI). Journal of Communication Disorders, 44, 186-199. https://doi.org/10.1016/j.jcomd is.2010.09.004.

Wallhagen, M. I. \& Reed, N. S. 2018. Implications of hearing care policy for nurses. J Geron Nurs. 44(9):9-14.

Zariqat, Ibrahim Abdullah Faraj (2005). Speech disorders and language diagnosis and treatment. Dar al-Fikr Publishing and Distribution. 